MSC 47D06, 49J15

DOI: $10.14529 /$ jcem 150307

\title{
THE NUMERICAL SOLUTION OF THE PROBLEMS OF OPTIMAL CONTROL TO NONSTATIONARY SOBOLEV TYPE MODEL IN RELATIVELY RADIAL CASE
}

\author{
A.N. Shulepov, South Ural State University, Chelyabinsk, Russian Federation, \\ andrewn92@mail.ru
}

In this paper we prove the existence of a unique optimal and hard control over solutions of Showalter - Sidorov problem for nonstationary model, which is described by Sobolev type equations. In this case, one of the operators in the equation is multiplied by a scalar function of the time-variable, besides stationary equation has a strong continuous degenerate resolving semigroup of operators.

Keywords: optimal control; Sobolev-type equations; relatively radial operator.

\section{Introduction}

In bounded domain $\Omega \subset \mathbb{R}^{n}$ with a bound $\partial \Omega$ from class $C^{\infty}$ consider the boundary value problem

$$
\Delta x(s, t)=x(s, t)=0, \quad(s, t) \in \partial \Omega \times[0, T]
$$

for partial differential equations [1]

$$
(\lambda-\Delta) x_{t}=\nu(t) \Delta x-i \nu(t) d \Delta^{2} x+u .
$$

Here the coefficients $\lambda, d \in \mathbb{R}$ describe the parameters of the system, vector function $u$ responds to external influences on the system and is a function of control.

The equation (2) is the equation of Sobolev type [2]. The Sobolev type equations with coefficients depending on the time was proposed in [3]. For the first time the optimal control for stationary Sobolev type equations was considered in [4]. Some technical challenges can be seen as an optimal control problem for nonstationary Sobolev-type equations [5].

In this paper the optimal control problem for the model (1), (2) are investigated with the help of abstract results. Let $\mathfrak{X}, \mathfrak{Y}$ and $\mathfrak{U}$ be Hilbert spaces. We define the operators $L$ and $M$ in the following way: $L \in \mathcal{L}(\mathfrak{X} ; \mathfrak{Y}), M \in \mathcal{C l}(\mathfrak{X} ; \mathfrak{Y})$.

Consider Showalter - Sidorov problem [6]

$$
P\left(x(0)-x_{0}\right)=0
$$

for Sobolev-type equation [2, 7]

$$
L \dot{x}(t)=a(t) M x(t)+u(t),(\operatorname{ker} L \neq\{0\}) \quad t \in[0, \tau] .
$$

Consider the penalty functional

$$
J(u)=\alpha \sum_{q=0}^{1} \int_{0}^{\tau}\left\|z^{(q)}(t)-z_{d}^{(q)}(t)\right\|_{\mathfrak{Z}}^{2} d t+(1-\alpha) \sum_{q=0}^{k} \int_{0}^{\tau}\left\langle N_{q} u^{(q)}(t), u^{(q)}(t)\right\rangle_{\mathfrak{U}} d t,
$$


where $\alpha \in(0,1), k=0,1, \ldots, p+1, z=C x$, the operator $C \in \mathcal{L}(\mathfrak{X} ; \mathfrak{Z})$, and $z_{d}=z_{d}(t, s)$ is an observation from some space of observations $\mathfrak{Z}$. Operators $N_{q} \in \mathcal{L}(\mathfrak{U}), q=0,1, \ldots, k$ are self-adjoint and positive definite operators. Note that $\alpha \in(0,1)$ and $(1-\alpha)$ are weighting coefficients purposes of optimal control are used to achieve planned targets observable quantity without abrupt changes (the first term in (5)) and to minimize the resources spent for the control (the second term in (5)). The application of abstract results obtained in [8] is represented in this paper.

\section{Relatively Radial Operators}

Recall the standard notation of the theory of relatively p-radial operators [2].

Definition 1. Sets $\rho^{L}(M)=\left\{\mu \in \mathbb{C}:(\mu L-M)^{-1} \in \mathcal{L}(\mathfrak{Y} ; \mathfrak{X})\right\}$ and $\sigma^{L}(M)=\mathbb{C} \backslash \rho^{L}(M)$ are called $L$-resolvent set and $L$-spectrum of $M$, respectively.

Definition 2. Operator-valued functions $(\mu L-M)^{-1}, R_{\mu}^{L}(M)=(\mu L-M)^{-1} L$, and $L_{\mu}^{L}(M)=L(\mu L-M)^{-1}$ are respectively called resolvent, right resolvent, and left resolvent of $M$ with respect to $L$ (or briefly $L$-resolvent, right $L$-resolvent, and left L-resolvent of $M$ ).

Denote

$$
R_{(\lambda, p)}^{L}(M)=\prod_{k=0}^{p} R_{\lambda_{k}}^{L}(M), L_{(\lambda, p)}^{L}(M)=\prod_{k=0}^{p} L_{\lambda_{k}}^{L}(M), \quad \lambda_{k} \in \rho^{L}(M)(k=\overline{0, p}) .
$$

Definition 3. An operator $M$ is called p-radial with respect to an operator $L$ (or briefly $(L, p)$-radial), whenever

(i) $\exists \omega \in \mathbb{R} \forall \mu>\omega \Rightarrow \mu \in \rho^{L}(M)$;

(ii) $\exists K>0 \forall \mu_{k}>\omega, k=\overline{0, p}, \forall n \in \mathbb{N}$

$$
\max \left\{\left\|\left(R_{(\mu, p)}^{L}(M)\right)^{n}\right\|_{\mathcal{L}(\mathfrak{X})},\left\|\left(L_{(\mu, p)}^{L}(M)\right)^{n}\right\|_{\mathcal{L}(\mathfrak{Y})}\right\} \leq \frac{K}{\prod_{k=0}^{p}\left(\mu_{k}-\omega\right)^{n}} .
$$

Also denote $\mathfrak{X}^{0}=\operatorname{ker} R_{(\mu, p)}^{L}(M), \mathfrak{Y}^{0}=\operatorname{ker} L_{(\mu, p)}^{L}(M), \quad L_{0}=\left.L\right|_{\mathfrak{X}^{0}}, M_{0}=\left.M\right|_{\operatorname{dom} M \cap \mathfrak{X}^{0}}$. Denote a closure of the linear $\operatorname{im} R_{(\mu, p)}^{L}(M)\left(\operatorname{im} L_{(\mu, p)}^{L}(M)\right)$ by $\mathfrak{X}^{1}\left(\mathfrak{Y}^{1}\right)$, and a closure of the linear $\mathfrak{X}^{0} \dot{+} \operatorname{im} R_{(\mu, p)}^{L}(M)\left(\mathfrak{Y}^{0} \dot{+} \operatorname{im} L_{(\mu, p)}^{L}(M)\right)$ in the norm of the space $\mathfrak{X}(\mathfrak{Y})$ by $\tilde{\mathfrak{X}}(\tilde{\mathfrak{Y}})$.

Definition 4. Strong continuous mapping $V^{\bullet}: \mathbb{R}_{+} \rightarrow \mathcal{L}(\mathcal{V})$ is called strong continuous semigroup of solving operators (or $C_{0}$-semigroup of solving operators) for some equation

(i) $V^{s} V^{t}=V^{s+t} \quad \forall s, t>0$;

(ii) $v(t)=V^{t} v_{0}$ is the solution of this equation for all $v_{0}$ from dense in $\mathcal{V}$ linear;

(iii) $s-\lim _{t \rightarrow t_{0}} V^{t} v=v \quad \forall v \in \mathcal{V}$.

Semigroup $\left\{V(t) \in \mathcal{L}(\mathcal{V}): t \in \overline{\mathbb{R}}_{+}\right\}$is called exponentially bounded with constants $C, \omega$, whenever

$$
\exists C>0 \quad \exists \omega \in \mathbb{R} \quad \forall t \in \overline{\mathbb{R}}_{+} \quad\|V(t)\|_{\mathcal{L}(\mathcal{V})} \leq C e^{\omega t} .
$$


Theorem 1. Let operator $M$ be $(L, p)$-radial. Then there exists a strong continuous semigroup of solving operators for the homogeneous equation (4) such that it is exponentially bounded with constants $K, \omega$ from Definition 4 and $a \equiv 1$, under review on the subspace $\tilde{\mathfrak{X}}$.

Remark 1. Operators of solving semigroup for equation (4) such that $a \equiv 1$ and $t>0$ can be represented as

$$
X^{t}=s-\lim _{k \rightarrow \infty}\left(\left(L-\frac{t}{k} M\right)^{-1} L\right)^{k}=s-\lim _{k \rightarrow \infty}\left(\frac{k}{t} R_{\frac{k}{t}}^{L}(M)\right)^{k},
$$

taking into account the amendments, which are discussed in paper [9].

Remark 2. A unit of the semigroup $\left\{X(t) \in \mathcal{L}(\tilde{\mathfrak{X}}): t \in \overline{\mathbb{R}}_{+}\right\}$is projector $P$ along $\mathfrak{X}^{0}$ on $\mathfrak{X}^{1}$.

Definition 5. An operator $M$ is called strong $(L, p)$-radial, whenever for all $\lambda, \mu_{0}, \mu_{1}, \ldots, \mu_{p}>\omega$

(i) there exists dense lineal $\stackrel{\circ}{\mathfrak{Y}}$ in $\mathfrak{Y}$ such that for all $y \in \stackrel{\circ}{Y}$

$$
\begin{gathered}
\left\|M(\lambda L-M)^{-1} L_{(\mu, p)}^{L}(M) y\right\|_{\mathfrak{Y}} \leq \frac{\operatorname{const}(y)}{(\lambda-\omega) \prod_{k=0}^{p}\left(\mu_{k}-\omega\right)} ; \\
\text { (ii) } \quad\left\|R_{(\mu, p)}^{L}(M)(\lambda L-M)^{-1}\right\|_{\mathcal{L}(\mathfrak{Y} ; \mathfrak{X})} \leq \frac{K}{(\lambda-\omega) \prod_{k=0}^{p}\left(\mu_{k}-\omega\right)} .
\end{gathered}
$$

Theorem 2. Let $M$ be strong $(L, p)$-radial operator. When

(i) $\mathfrak{X}=\mathfrak{X}^{0} \oplus \mathfrak{X}^{1}, \mathfrak{Y}=\mathfrak{Y}^{0} \oplus \mathfrak{Y}^{1}$;

(ii) the operators $L_{k}=\left.L\right|_{\mathfrak{X}^{k}} \in \mathcal{L}\left(\mathfrak{X}^{k} ; \mathfrak{Y}^{k}\right), \quad M_{k}=\left.M\right|_{\operatorname{dom} M_{k}} \in \mathcal{C l}\left(\mathfrak{X}^{k} ; \mathfrak{Y}^{k}\right)$,

$\operatorname{dom} M_{k}=\operatorname{dom} M \cap \mathfrak{X}^{k}, k=0,1$;

(iii) there exist operators $M_{0}^{-1} \in \mathcal{L}\left(\mathfrak{Y}^{0} ; \mathfrak{X}^{0}\right)$ and $L_{1}^{-1} \in \mathcal{L}\left(\mathfrak{Y}^{1} ; \mathfrak{X}^{1}\right)$.

\section{Optimal Control}

Definition 6. A vector function $x \in H^{1}(\mathfrak{X})=\left\{x \in L_{2}(0, \tau ; \mathfrak{X}): \dot{x} \in L_{2}(0, \tau ; \mathfrak{X})\right\}$ is called a strong solution of equation (4), whenever it satisfies (4) almost everywhere in the interval $(0, \tau)$. Strong solution $x=x(t)$ of equation (4) is called strong solution to the Showalter-Sidorov problem (3), (4), whenever it satisfies (3).

Denote $\mathbb{N}_{0} \equiv \mathbb{N} \cup\{0\}$. Construct the Hilbert space

$$
H^{p+1}(\mathfrak{Y})=\left\{y \in L_{2}(0, \tau ; \mathfrak{Y}): y^{(p+1)} \in L_{2}(0, \tau ; \mathfrak{Y}), p \in \mathbb{N}_{0}\right\}
$$

with the scalar product $[y, z]=\sum_{q=0}^{p+1} \int_{0}^{\tau}\left\langle y^{(q)}, z^{(q)}\right\rangle_{\mathfrak{Y}} d t$.

Suppose that $(L, p)$-radial operator $M$ is strong for all $x_{0} \in \mathfrak{X}$ and $f \in H^{p+1}(\mathfrak{Y})$. Then, by results in [8], there exists a unique strong solution $x \in H^{1}(\mathfrak{X})$ of Showalter - Sidorov 
problem (3) for equation (4) and it has a form

$$
\begin{aligned}
& x(t)=X^{\int_{0}^{t} a(\zeta) d \zeta} P x_{0}+\int_{0}^{t} X_{s}^{t} a(\zeta) d \zeta L_{1}^{-1} Q(f(s)+B u(s)) d s- \\
& -\sum_{k=0}^{p}\left(M_{0}^{-1} L_{0}\right)^{k} M_{0}^{-1}(I-Q)(A D)^{k} A(f(t)+B u(t)) .
\end{aligned}
$$

Consider spaces $\mathfrak{X}=\stackrel{\circ}{W_{2}^{1}}(\Omega), \mathfrak{Y}=W_{2}^{-1}(\Omega)$.

Let $\lambda, d \in \mathbb{R}$ be fixed, then the operators take the form $L=\lambda-\Delta, M=\Delta-i d \Delta^{2}$, where $\Delta$ is Laplace operator. It is shown in [1] that operator $L \in \mathcal{L}(\mathfrak{U} ; \mathfrak{F})$, operator $M \in \mathcal{C l}(\mathfrak{U} ; \mathfrak{F})$, and $\operatorname{dom} M=\left\{x \in W_{2}^{3}(\Omega): \Delta x(s, t)=x(s, t)=0, s \in \partial \Omega\right\}$. We denote by $\left\{\lambda_{k}\right\}$ the sequence of eigenvalues of the homogeneous Dirichlet problem for Laplace operator $\Delta$ in $\Omega$. Sequence $\left\{\lambda_{k}\right\}$ is index eigenvalues with respect to their multiplicities by descending. Denote by $\left\{\varphi_{k}\right\}$ an orthonormal (in terms of $L_{2}(\Omega)$ ) sequence of corresponding eigenfunctions, $\varphi_{k} \in C^{\infty}(\Omega), k \in \mathbb{N}$.

Lemma 1. Operator $M$ is strong $(L, 0)$-radial for all $\lambda, d \in \mathbb{R}$.

Proof of Lemma 1 is given in [1].

Definition 7. Vector function $v \in H_{\partial}^{1}(\mathfrak{U})$ is called optimal control of model (1),(2) by solutions of the problem (3), (4), whenever

$$
J(v)=\min _{(x, u) \in \mathcal{X} \times H_{\partial}^{1}(\mathfrak{U})} J(u),
$$

where pairs $(x, u) \in \mathfrak{X} \times H_{\partial}^{1}(\mathfrak{U})$ satisfy (3), (4) and $H_{\partial}^{1}(\mathfrak{U})$ is closed, convex subset in $H^{1}(\mathfrak{U})$.

Theorem 3. Let $M$ be strong $(L, p)$-radial, $p \in \mathbb{N}_{0}$, function $a \in C^{p+1}\left([0, \tau) ; \mathbb{R}_{+}\right)$. When for all $x_{0} \in \mathfrak{X}$ there exists unique optimal control $v \in H_{\partial}^{p+1}(\mathfrak{U})$ for model (1),(2) of problem $(3),(5),(6)$.

\section{Numerical Experiment}

We calculate minimum of the functional $J(u)$ on the subset of admissible controls using system of Maple 18 having built-in procedure for finding extrema of functions of several variables. Let us consider an example, which illustrates the results obtained above.

In domain $\Omega=\left\{\left(s_{1}, s_{2}\right) \in \mathbb{R}^{2}: 0 \leq s_{1} \leq l_{1}, \quad 0 \leq s_{2} \leq l_{2}\right\}$ consider in a cylinder $\Omega \times \mathbb{R}$ Dirichlet problem

$$
x\left(s_{1}, s_{2}, t\right)=\Delta x\left(s_{1}, s_{2}, t\right)=0 \quad\left(s_{1}, s_{2}, t\right) \in \partial \Omega \times \mathbb{R}
$$

for equation

$$
(\lambda-\Delta) x_{t}=\nu(t)\left(\Delta x-i \Delta^{2} x\right)+u
$$

with Showalter - Sidorov condition

$$
P\left(x(0)-x_{0}\right)=\sum_{k \in \mathbb{N} \backslash\left\{l: \lambda_{l}=\lambda\right\}}\left\langle x(0)-x_{0}, \psi_{k}\right\rangle \psi_{k} .
$$


Parameters of the equation are defined as follows:

$$
\begin{gathered}
\Omega=\left\{\left(s_{1}, s_{2}\right) \in \mathbb{R}^{2}: 0 \leq s_{1} \leq 1,0 \leq s_{2} \leq 1\right\}, \\
N=2, \quad M=2, \quad \lambda=3 \pi^{2}, \quad \nu(t)=\frac{1}{t+1}, \quad \alpha=\frac{8}{10}, \quad C=\mathbb{I}, \quad N_{q}=\mathbb{I} .
\end{gathered}
$$

Initial condition is

$$
x_{0}\left(s_{1}, s_{2}\right)=\sin \left(\pi s_{1}\right) \sin \left(\pi s_{2}\right)+\sin \left(2 \pi s_{1}\right) \sin \left(\pi s_{2}\right)+\sin \left(2 \pi s_{1}\right) \sin \left(2 \pi s_{2}\right),
$$

planned state is

$$
z_{d}\left(s_{1}, s_{2}, t\right)=-\frac{5}{4} \sin \left(2 \pi s_{1}\right) \sin \left(\pi s_{2}\right)+\sin \left(\pi s_{1}\right) \sin \left(\pi s_{2}\right)
$$

The minimum value of the functional $J_{\min }=0,2576$ on the set of admissible controls which is determined by the condition $\sum_{j=1}^{M}\left(u_{j}^{2}(t)+\dot{u}_{j}^{2}(t)\right) \leqslant 1$.

Construct a solution $x\left(s_{1}, s_{2}, t\right)$ obtained above and planned state $z_{d}\left(s_{1}, s_{2}, t\right)$ (see Fig.).

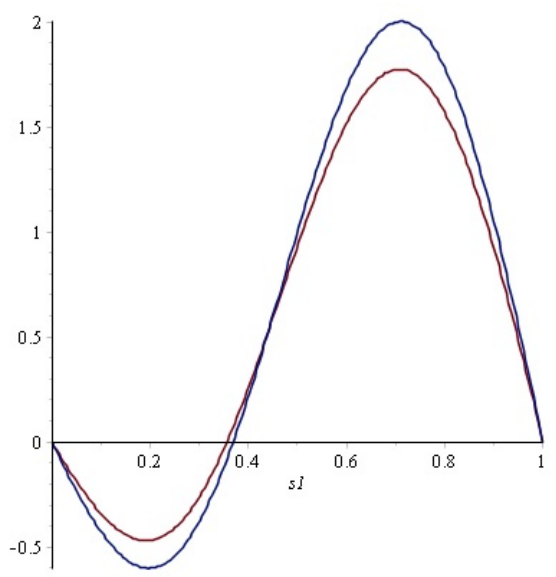

Required observation and solution of the optimal control problem at $s_{2}=\frac{1}{2}$ at the final time

\section{References}

1. Sagadeeva M.A., Shulepov A.N. On a Non-Linear Model Based on the Relative Radial Equation of Sobolev Type. Bulletin of Odessa National University. Mathematics and Mechanics, 2013, vol. 18, no. 2 (18), pp. 35-43. (in Russian)

2. Sviridyuk G.A., Fedorov V.E. Linear Sobolev Type Equations and Degenerate Semigroups of Operators. Utrecht, Boston, VSP, 2003.

3. Sagadeeva M.A. Sagadeeva M.A. Issledovanie ustoychivosti resheniy lineynykh uravneniy sobolevskogo tipa: dis...kand. fiz.-mat. nauk [Investigation of Solutions Stability for Linear Sobolev Type Equations]. Chelyabinsk, 2006. 
4. Sviridyuk G.A., Efremov A.A. An Optimal Control Problem for a Class of Linear Equations of Sobolev Type. Russian Mathematics (Izvestiya VUZ. Matematika), 1996, vol. 40, no. 12, pp. 60-71.

5. Shestakov A.L., Sviridyuk G.A., Sagadeeva M.A. Reconstruction of a Dynamically Distorted Signal with Respect to the Measuring Transducer Degradation. Applied Mathematical Sciences, 2014, vol. 8, no. 41-44, pp. 2125-2130.

6. Sviridyuk G.A., Zagrebina S.A. Showalter - Sidorov Problem as a Phenomenon of Sobolev Type Equations. The Bulletin of Irkutsk State University. Series: Mathematics, 2010, vol. 3, no. 1, pp. 104-125. (in Russian)

7. Favini A., Yagi A. Degenerate Differential Equations in Banach Spaces. New York, Basel, Hong Kong, Marcel Dekker, Inc, 1999.

8. Sagadeeva M.A., Shulepov A.N. The Problem of Optimal and Hard Control Solutions of a Special Type of Non-Stationary Equations of Sobolev Type. Journal of Samara State Technical University, Ser. Physical and Mathematical Sciences, 2014, no. 2 (35), pp. 33-38. (in Russian)

9. Sagadeeva M.A., Shulepov A.N. Approximation of Degenerate $C_{0}$-Semigroup. Bulletin of the South Ural State University. Series: Mathematical Modelling, Programming 86 Computer Software, 2013, vol. 6, no. 2, pp. 133-137. (in Russian).

Andrew N. Shulepov, postgraduate student, department of equation of mathematical physics, South Ural State University, Chelyabinsk, Russian Federation, andrewn92@mail.ru.

\section{ЧИСЛЕННОЕ РЕШЕНИЕ ЗАДАЧИ ОПТИМАЛЬНОГО УПРАВЛЕНИЯ ОДНОЙ НЕСТАЦИОНАРНОЙ МОДЕЛИ СОБОЛЕВСКОГО ТИПА В ОТНОСИТЕЛЬНО РАДИАЛЬНОМ СЛУЧАЕ}

\section{А.Н. Шулепов}

В работе рассмотрена модель, описываемая неклассическим уравнением математической физики, с коэффициентами зависящими от времени. Такие уравнения часто называют уравнениями соболевского типа в относительно радиальном случае, т.е. стационарное уравнение обладает разрешающей сильно непрерывной вырожденной полугруппой. Показано существование единственного оптимального управления решениями задачи Шоуолтера-Сидорова для нестационарной модели.

Ключевые слова: оптимальное управление; нестачионарные уравнения соболевского типа; относительно радиальный случай. 


\section{Литература}

1. Сагадеева, М.А. Об одной нелинейной модели на основе относительно радиального уравнения соболевского типа / М.А. Сагадеева, А.Н. Шулепов // Вестник Одесского национального университета. Математика и механика. - 2013. - Т. 18, вып. 2 (18). - С. 35-43.

2. Sviridyuk, G.A. Linear Sobolev Type Equations and Degenerate Semigroups of Operators / G.A Sviridyuk, V.E. Fedorov. - Utrecht, Boston: VSP. - 2003.

3. Сагадеева, М. А. Исследование устойчивости решений линейных уравнений соболевского типа: дисс. ... канд.физ.-мат.наук / М.А. Сагадеева, ЧелГУ. - Челябинск, 2006.

4. Свиридюк, Г.А. Задача оптимального управления для одного класса линейных уравнений типа Соболева / Г.А. Свиридюк, А.А. Ефремов // Известия вузов. Математика. - 1996. - Т. 40, № 12. - С. 75-83.

5. Shestakov, A.L. Reconstruction of a Dynamically Distorted Signal with Respect to the Measuring Transducer Degradation // A.L. Shestakov, G.A. Sviridyuk, M.A. Sagadeeva // Applied Mathematical Sciences. - 2014. - V. 8, № 41-44. C. $2125-2130$.

6. Свиридюк Г.А., Загребина С.А. Задача Шоуолтера - Сидорова как феномен уравнений соболевского типа / Г.А. Свиридюк, С.А. Загребина // Известия Иркутского государственного университета. Серия: Математика. - 2010. - Т. 3, № 1. C. $104-125$.

7. Favini, A. Degenerate Differential Equations in Banach Spaces / A. Favini, A. Yagi. - New York; Basel; Hong Kong: Marcel Dekker, 1999.

8. Сагадеева, М.А. Задачи оптимального и жесткого управления решениями специального вида нестационарных уравнений соболевского типа / М.А. Сагадеева, А.Н. Шулепов // Вестник СамГТУ. Серия: Физико-математические науки. 2014. - № 2 (35). - C. 33-38.

9. Сагадеева, М.А. Аппроксимации вырожденных $C_{0}$-полугрупп / M.А. Сагадеева, А.Н. Шулепов // Вестник ЮУрГУ. Серия: Математическое моделирование и программирование. - 2013. - Т. 6, № 2. - С. 133-137.

Шулепов Андрей Николаевич, аспирант, кафедра уравнений математической физики, Южсно-Уральский государственный университет (ә. Челябинск, Российская федерачия), andrewn92@mail.ru.

Поступила в редакиию 25 августа 2015 г. 